\section{Systemic toxicity from topically applied salicylic acid}

Topically applied salicylic acid has enjoyed long and extensive usage as an agent to enhance desquamation in various hyperkeratotic skin diseases. In some of these disorders much of the skin surface may be affected, resulting in the potential for significant percutaneous absorption of the drug. We describe a patient who gradually developed evidence of severe salicylate toxicity while being treated with topical salicylic acid. Consequent on a recent letter in the $B M \mathcal{F}^{1}$ this report serves as a reminder of a problem which, although recognised, ${ }^{2}$ may be unfamiliar to the current generation of dermatologists. It also shows strikingly the systemic absorption that may result from compounds applied to the skin.

\section{Case history}

The patient was a 30-year-old man from Mauritius with a history of extensive ichthyosis starting within a few days of birth. Examination showed a small man (weight $46 \mathrm{~kg}$, height $144 \mathrm{~cm}$ ) with severe generalised ichthyosis, bilateral ectropion, and gross thickening of the horny layer of the palms and soles. Renal function and liver function tests (including serum albumin estimation - $48 \mathrm{~g} / \mathrm{l})$ were normal. Histologically the skin showed hypergranulosis and pronounced hyperkeratosis. A diagnosis of autosomal recessive non-bullous ichthyosiform erythroderma of the lamellar type was made. Epidermal kinetic studies showed epidermopoiesis to be at the upper limit of normal, and thus the basis for his ichthyosis appeared to be retarded desquamation. He was therefore started on topical salicylic acid in cetomacrogol, initially at a concentration of $4 \%$, daily to the right leg. The rest of his skin was treated with emollients.

The topical salicylic acid was gradually increased to $12 \%$ in cetomacrogol applied to the trunk and limbs (except the soles) twice daily (approximate daily dose $150 \mathrm{~g}$ ). The patient remained on this regimen for 20 days. Serum salicylate concentrations during the second half of this period (see fig) were

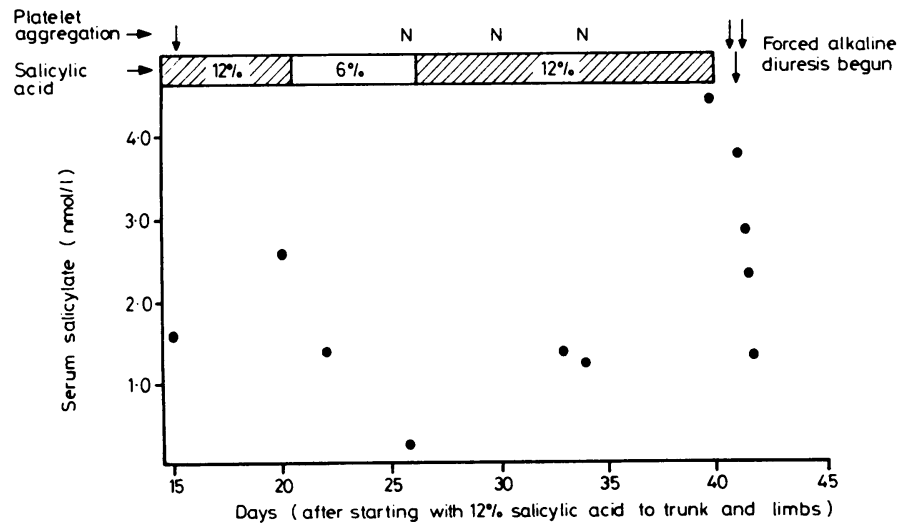

Serum salicylate concentrations and results of platelet aggregation tests ( $n=$ normal; $\downarrow=$ moderate impairment; $\downarrow \downarrow=$ severe impairment) in patient treated with topical salicylic acid. ( $1 \mathrm{mmol}$ serum salicylate $/ 1 \approx 13.8$ $\mathrm{mg} / 100 \mathrm{ml}$.)

1.6 and $2.57 \mathrm{mmol} / 1(22.1$ and $35.5 \mathrm{mg} / 100 \mathrm{ml})$ (upper limit of therapeutic range $2.2 \mathrm{mmol} / 1 ; 30.4 \mathrm{mg} / 100 \mathrm{ml}$ ). At this stage the patient's platelets showed impairment of collagen-stimulated aggregation (quantitative in-vitro optical density method). In view of this and since his skin had greatly improved the strength of the topical salicylic acid was reduced to $6 \%$. Serum salicylate concentrations fell. His ichthyosis, however, apparently worsened and after six days $12 \%$ salicylic acid was reinstituted. Twelve days later, although the serum salicylate values had twice been reported in the middle of the therapeutic range, he began to complain of malaise, nausea, epigastric discomfort, tinnitus, and slight deafness. Examination disclosed mild sensorineural deafness and he was noted to be hyperventilating. The serum salicylate concentration was $4.55 \mathrm{mmol} / 1(62.8 \mathrm{mg} / 100 \mathrm{ml})$ and the platelet aggregation test showed considerable quantitative impairment. He had a metabolic acidosis (serum bicarbonate $17 \mathrm{mmol}(\mathrm{mEq} / \mathrm{l})$. Topical salicylic acid was stopped and an intravenous infusion forced alkaline diuresis begun. His condition rapidly improved.

\section{Comment}

The pronounced percutaneous absorption seen in this patient was undoubtedly related to both the high concentration of salicylic acid used and the fact that it was applied to $85-90 \%$ of the body surface.
An exacerbating factor would have been a high "skin surface area: body mass" ratio resulting from the patient's small size. In these respects the patient was similar to the case reported by Aspinall and Goel. ${ }^{1}$ We expected that appreciable absorption of salicylic acid might occur but were surprised by its delay and severity. The severity may have been due in part to a thinner stratum corneum (at that stage of the treatment) and to decreased renal clearance of salicylate secondary to its induction of a metabolic acidosis. Weiss and Lever ${ }^{2}$ cited 13 deaths reported to be due to topical salicylic acid treatment. Patients given frequent high concentrations of salicylic acid topically over a large surface area thus require close clinical and biochemical monitoring.

Our case provides a further reminder that the topical application of drugs, particularly to abnormal skin, may result in toxicity comparable to that seen with systemic administration.

Dr R Marks, Cardiff, conducted the epidermal kinetic studies on this patient.

1 Aspinall, J B, and Goel, K M, British Medical fournal, 1978, 2, 1373.

2 Weiss, J F von, and Lever, W F, Archives of Dermatology, 1964, 90, 614.

(Accepted 18 fanuary 1979)

Institute of Dermatology and St John's Hospital for Diseases of the Skin, London E9 6BX

M G DAVIES, BSC, MRCP, senior registrar

D VELLA BRIFFA, MD, research associate

$M$ W GREAVES, PHD, FRCP, professor of dermatology

\section{Controlled trial of cimetidine in acute upper gastrointestinal bleeding}

The histamine $\mathrm{H}_{2}$-receptor antagonist cimetidine is a potent inhibitor of gastric acid and pepsin secretion. ${ }^{1}$ It might therefore prevent peptic digestion of blood clot attached to an eroded vessel in acute upper gastrointestinal bleeding. Prophylactic administration to patients with fulminant hepatic failure reduces the incidence of subsequent bleeding from gastric and oesophageal erosions. ${ }^{2} \mathrm{We}$ have therefore conducted a prospective, double-blind trial of cimetidine in an unselected series of 69 patients admitted with acute upper gastrointestinal bleeding. Monitoring included central venous pressure (CVP) measurements as a sensitive indicator of recurrent bleeding, ${ }^{3}$ because recurrent bleeding is the single most important factor determining mortality.

\section{Patients, methods, and results}

All patients admitted with acute upper gastrointestinal bleeding were entered into the trial before they left the casualty department. All gave written informed consent. Patients excluded were $(a)$ those whose bleeding was so profuse that immediate surgery was indicated, and $(b)$ those whose last evidence of bleeding was more than 72 hours before admission.

Cimetidine (or matching placebo) was given intravenously for 48 hours $-200 \mathrm{mg}$ immediately, then $250 \mathrm{mg}$ every six hours-and then by mouth for five days $-400 \mathrm{mg}$ thrice daily and $800 \mathrm{mg}$ at bedtime. The trial was terminated at the end of this period, or earlier if there had been evidence of rebleeding. The initial bleed was designated severe if the patient fulfilled any of the following criteria on admission: (a) systolic blood pressure below $100 \mathrm{~mm} \mathrm{Hg}$, (b) pulse rate exceeding 110 beats/min, and (c) a haemoglobin concentration below $8 \mathrm{~g} / \mathrm{dl}$. Whenever possible patients were admitted to the intensive care unit, where a CVP line was inserted and its position checked radiologically. Pulse rate, blood pressure, and CVP were checked hourly for the first 48 hours. Five criteria were used to diagnose further bleeding: (1) failure of the CVP to reach a sustained level of $+1 \mathrm{~cm}$ water above the manubriosternal joint after seven units of blood ${ }^{3}$ (2) a fall in CVP from this level to less than $-4 \mathrm{~cm}$ water over two hours or less $\mathrm{s}^{3}$; (3) a fresh haematemesis; (4) a sudden rise in pulse rate of over 20 beats/min or a sudden fall in systolic blood pressure of more than $20 \mathrm{~mm} \mathrm{Hg}$; and (5) active bleeding detected by endoscopy, which was routinely carried out in the first 24 hours after admission.

Sixty-nine patients completed the trial : 33 received cimetidine, of whom 12 $(36 \%)$ rebled, and 36 placebo, of whom $10(28 \%)$ rebled. Fifteen patients in the cimetidine group had had a severe initial bleed, and of these 10 rebled. Thirteen patients in the placebo group had had a severe bleed, and of these five rebled. Eighteen patients in the cimetidine group had had a mild initial 
Results of treatment in the two groups subdivided according to endoscopic diagnosis

\begin{tabular}{|c|c|c|c|c|}
\hline \multirow{2}{*}{ Lesion } & \multicolumn{2}{|c|}{ Cimetidine $(\mathrm{n}=33)$} & \multicolumn{2}{|c|}{ Placebo $(n=36)$} \\
\hline & Rebleed & No rebleed & Rebleed & No rebleed \\
\hline $\begin{array}{l}\text { Duodenal ulcer } \\
\text { Gastric ulcer } \\
\text { Oesophagitis } \\
\text { Mallory-Weiss } \\
\text { Gastric erosions } \\
\text { Stomal ulcer } \\
\text { Gastric volvulus } \\
\text { Unknown }\end{array}$ & $\begin{array}{l}7 \\
1 \\
3 \\
1\end{array}$ & $\begin{array}{l}6 \\
3 \\
4 \\
5 \\
1 \\
1 \\
1\end{array}$ & $\begin{array}{l}6 \\
2 \\
2\end{array}$ & $\begin{array}{l}9 \\
6 \\
3 \\
2 \\
3\end{array}$ \\
\hline Total & 12 & 21 & 10 & 26 \\
\hline
\end{tabular}

bleed, and of these two rebled. Twenty-three patients in the placebo group had had a mild initial bleed, and of these five rebled. The table gives the results according to endoscopic diagnosis. No effect from cimetidine was apparent in any subgroup.

\section{Comment}

Our results do not support a policy of routinely treating with cimetidine all patients admitted to hospital with acute upper gastrointestinal bleeding. Nevertheless, we cannot exclude the possibility of benefit in selected patients, since the diagnostic subgroups were small.

We thank the clinical research department of Smith Kline and French Laboratories Limited for supplies of cimetidine and matching placebo.

1 Burland, W L, et al, British fournal of Clinical Pharmacology, 1975, 2, 481. 2 MacDougall, B R D, Bailey, R J, and Williams, R, Lancet, 1977, 1, 617.

3 Northfield, T C, and Smith, T, Lancet, 1970, 2, 584

4 Jones, F A, Gastroenterology, 1956, 30, 166.

(Accepted 22 fanuary 1979)

\section{Norman Tanner Gastroenterology Unit, St James's Hospital, London} SW12 8HT

R G PICKARD, MCHIR, FRCs, senior surgical registrar

ISABEL SANDERSON, MRCP, senior medical registrar

MARIE SOUTH, FRCS, senior surgical registrar

J S KIRKHAM, MCHIR, FRCS, consultant surgeon

T C NORTHFIELD, MD, FRCP, consultant physician and senior lecturer in medicine

\section{Endogenous anxiety and circadian rhythms}

Nikitopoulou and Crammer ${ }^{1}$ showed that diurnal body temperature curves change in manic-depressive illness, and suggested that this change in circadian rhythm might be related to the diurnal variation in depth of mood that is also associated with early morning waking in depression. They thought that these findings suggested a disturbance in brain centres or neurological organ function rather than in scattered synapses or cellular function. In $1977^{2}$ I drew attention to the possibility that some anxiety states might fall into the same endogenous category of mood change, since they exhibited increasing intensity of emotion towards evening associated with difficulty in getting to sleep at night. I recognised, however, the difficulties of carrying out suitable body temperature studies to support this hypothesis. Recently a patient with an anxiety state co-operated in such a study.

\section{Case report}

In 1978 a 25 -year-old, happily married man who was employed as a computer scientist was referred to me. He had had a chronic intermittent anxiety for six years, which had worsened considerably in the last six months. A maternal aunt and possibly his mother had a history of similar severe nervousness, though three sisters and two brothers were well. Psychological environmental stress did not account for his anxiety. Serum thyroxine concentration, triiodothyronine uptake, and free thyroxine index were within normal limits, as were the results of screening for excess catecholamines. He

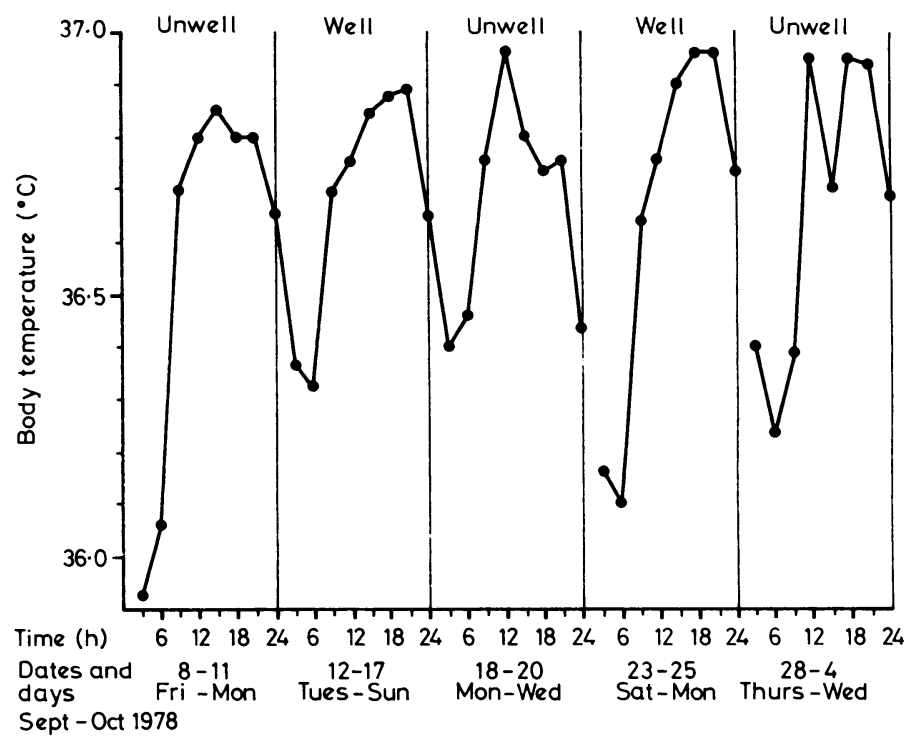

Three-hourly body temperature curves over 24 hours. Vertical lines separate average curves of each period of several consecutive days during which the patient was well or unwell.

was taking lorazepam (Ativan), $2.5 \mathrm{mg}$ twice daily, prescribed by his family doctor, and felt comparatively well on waking in the mornings, his symptoms becoming more obtrusive in the late afternoon and continuing until he fell asleep in the early hours of the morning. Lorazepam helped to reduce his symptoms but did not clear them, even when I suggested that he should take both his daily doses towards evening.

His symptoms were of nameless dread, apprehensive tension, loss of appetite, nausea, diarrhoea, and difficulty in getting to sleep. $\mathrm{He}$ was interested in their possible relation to body circadian rhythms, and agreed to chart each symptom on a three-point scale as "absent," "moderate," or "marked," while taking his body temperature by mouth three-hourly, which he did daily from 26 August to 6 October. He continued to take both his daily $2 \cdot 5-\mathrm{mg}$ doses of lorazepam towards evening. An attempt after 6 October to do without medication failed because his symptoms immediately worsened.

\section{Comment}

The records that he kept for six weeks unexpectedly showed that even during such a relatively short time his condition fluctuated every few days, in a way unaccounted for by weekends. After he had settled into his recording routine five separate periods, each of several consecutive days, could be identified, during which he was either continuously symptom free or moderately to severely anxious every evening. Following the method of Nikitopoulou and Crammer, the daily body temperature recordings for each of these five periods were averaged to give 24-hour temperature curves (see figure). The curves during the two periods when he was well were smoother and peaked at between 6 and $9 \mathrm{pm}$, whereas in the three periods when he was unwell they were more disorganised and tended to peak some 6-9 hours earlier.

These findings do not conclusively show a relation between endogenous anxiety and a change in diurnal body temperature rhythm, but may provide a basis for extending studies on untreated or otherwise suitable patients. Though I have seen other patients with the same evening patterns, none have yet been suitable for this purpose. If an endogenous basis can thus be conclusively shown for some anxiety states, however, and the central nervous site ${ }^{3}$ for this firmly established, it might provide a stimulus to research on anxiolytic preparations that could be more effective than those we have at present.

1 Nikitopoulou, G, and Crammer, J L, British Medical fournal, 1976, 1, 1311.

2 Crawford, J P, British Medical fournal, 1977, 2, 1544.

3 Crawford, J P, Medical Hypotheses, 1978, 4, 311.

(Accepted 25 fanuary 1979)

Stone House Hospital, Dartford, Kent DA2 6AU

J P CRAWFORD, MDPSYCH, MRCP, consultant psychiatrist 